\section{ELECTROCHEMICAL PROCESSES}

\section{Electrochemistry}

By J. Koryta, J. Dvorak, and V. Bohackova. Pp. xv + 350. (Methuen: London, September 1970.) 105s.

Texтвоoks and monographs on electrochemistry are fairly common but here at long last is one that can be recommended. The material for the book originated in lectures given at the Charles University in Prague. The four principal chapters deal with equilibria in electrolyte solution, transport phenomena, equilibria in heterogeneous clectrochemical systems and the kinetics of electrochemical processes.

Although first year undergraduates might find the going rather tough, the level is suitable for a third year course or for postgraduates starting on electrochemical research. For instance, there are useful sections on such topies as the acidity function, convective diffusion and experimental methods in electrochemical kinetics; there is also a valuable discussion of the double layer, and the authors quite rightly devote as much space to diffusion as to conductivity in electrolyte solutions. 'There is necessarily a large number of equations but the mathematics is well explainod and there is a useful appendix on the solution of the differential equations found in electrochemistry. The authors' descriptions are concise and they certainly believo in using the deep end: the Debye-Hückel theory starts on page 17 and the pace continues to be as fast. But the topics are ordered in a logical rather than in a traditional or historical fashion.

The standard of the English is good and there are plenty of helpful diagrams. One can criticize one or two small points; for instance, there is only just over a page on the actual measurement of activity coefficients and the examples of important electrode processes are too briefly described. I would have preferred more references than the twenty or so key review articles given at the end of each chapter. But all in all this is a book to be recommended for teachers and students. Professor Koryta and his co-authors will now have to get busy re-writing the book in SI units, no doubt a more difficult task than translating it into English.

W. J, Albery

\section{RADIATION CHEMISTRY}

The Radiation-induced Decomposition of Inorganic Molecular lons

By Everett R. Johnson. Pp. ix + 144. (Gordon and Breach: New York and London, August 1970.) 145s; $\$ 17.40$.

I DID not immediately comprehend from the title that this was a book about the chemical effects of high energy radiation on inorganic solids. At a first glance and even on reflexion it is easy to confuse the stable molecular ions of this book with the transient molecular ions which have little or no connexion with the subject matter of the book. Indeed, the investigation of such transient molecular ions, both positive and negative, constitutes one of the most active areas of chemical physics at the present time. Workers in this field would certainly feel cheated if they bought this book, and in any future edition it would certainly be advisable to select a less ambiguous title.

Title apart, the book is most useful and presents in a most readable manner the chomical changes induced by ionizing radiations in inorganic solids such as nitrates, chlorates, perchlorates, bromates, azides and permanganates. An introductory chapter gives certain background material in solid state chemistry, and this is followed by a general account of the factors affecting the radiation decomposition of inorganic solids. Thereafter, the solids are discussed individually according to the nature of the anion. The account is both descriptive and critical and the book can be recommended to graduate students who are freshly entering the field. The subject, which has not progressed far beyond the descriptive stage, is still fraught with inconsistencies and remains removed from the main stream of chemistry. Nevertheless, the author has made a detcrmined and praiseworthy attempt to systematize the available data. The major limitations are inherent in the subject itself.

Glyn O. PhILlips

\section{WORK OF A MASTER}

\section{Gesammelte Abhandlungen}

By David Hilbert. Second edition: Band 1: Zahlentheorie. Pp. xvi+539. Band 2: Algebra, Invariantentheorie, Geometrie. Pp. viii +453. Band 3: Analysis, Grundlagen der Mathematik, Physik, Verschiedenes, Lebensgeschichte. Pp. vii + 435. (Springer-Verlag: Berlin and New York, 1970.) DM98; $\$ 27$ the set.

THe firm of Springer has given us, in the samo year as Constance Reid's excellent life of Hilbert, a reprint of the master's collected papers, first published in 1932-5. It would be an exaggeration to say that these papers cover the whole field of mathomatical development in the half-century 1885-1935; for instance, Hilbert seems to have had little interest in the Lebesgue thcory. But nobody else of the time could match his power of making deep and fundamental penetrations on so wide a front.

Arrangement is not chronological, but by topics. The first volume deals largely with his serics of great memoirs, establishing the principles of class field theory. It ends, however, with a dessert dish in the proof of Waring's conjecture; the first note in 1909 used a 25-ple integral, but the second note in the same year made a 5-ple integral suffice. In the second volume, we find the three pages in which Hilbert disposed of Gordan's theorem on the existence of a finite basis for invariants, a proof which provoked Gordan to remark "This is not mathematics, this is theology". The whole contents of this volume are set in perspective by two surveys, one by van der Waerden on the algebraic part, and one by Schmidt on the geometric work, principally the axiomatic formalization of geometry.

Volume three is a rich miscellany. The papers on analysis deal chiefly with the rehabilitation of Dirichlet's principle, and some axiomaties. Then there is the famous paper given to tho international congress in Paris in 1900 , the list of unsolved problems which governed the direction of much of twentieth-century mathematics. The memoirs on integral equations, later collected into a book, are not included, but there is a most valuable survey of this topic, up to and including Hilbert's powerful contributions, by Hellinger.

The volumes have been printed with the publisher's usual care and skill, and any library with mathematical pretensions, however meagre, must find room for thom.

T. A. A. Broadbent

\section{REVISED KUHN}

\section{Atomic Spectra}

By H. G. Kuhn. Second edition. Pp. xvii +472. (Longman: London, January 1970.) 105s.

THe publication of a second edition of Atomic Spectra indicates that the book has found its place in the physics literature in that it covers the subject more thoroughly than the more general textbooks while being less mathematical than the more specialized texts such as that by Condon and Shortley.

For some years now the principal trend in high resolution atomic spectra has been the use of radio frequency 